\title{
Analysis of Damage Characteristics and Strong Ground Motion of Jiuzhaigou (Ms7.0) Earthquake
}

\author{
Sen Qiao, Xueliang Chen, Aiwen Liu, Tiefei Li, Zongchao Li, Zhen Zhang, Quanbo Luo
} Institute of Geophysics, China Earthquake Administration, Beijing 100081, China

\section{九寨沟 7.0 级地震震害特征及强地面运动分析}

\author{
乔森，陈学良，刘爱文，李铁飞，李宗超，张振，罗全波
}

中国地震局地球物理研究所，北京 $100081 ， 中$ 国

\begin{abstract}
Taking Jiuzhaigou after the earthquake disaster investigation data and the basis of strong earthquake records, we analyzed the characteristics of earthquake damage and the distribution characteristics of strong ground motion parameter PGA in this paper. The results of the investigation show that the earthquake caused a great loss to Jiuzhaigoucounty. Some areas have been hit by landslides, such as rock rolling and other disasters. From the analysis of ground motion characteristics, the seismic damage intensity of this earthquake is smaller than that of the other same magnitude. The overall destructive degree is smaller and the ground motion is also attenuated faster.
\end{abstract}

Keyword: strong ground motion observation, disaster investigation, strong ground motion, characteristic of disaster.

\section{摘要}

本文以九寨沟震后灾害调查资料以及 强地震观测资料为基础, 综合分析了九寨沟 地震的强地面运动特征及震害特征。震害调
查结果表明, 此次地震给九寨沟县造成了较 大的损失，局部地区山体滑坡，巨石滚落等 灾害较多。从强地面运动特征来看, 此次地 震的地震破坏强度比之前同等震级的地震 要小, 整体破坏性程度也要小, 地震动衰减 较快。

关键词: 强震观测; 震害调查; 强地面运动;

震害特征

1. 引言

2017 年 8 月 8 日 21 时 19 分, 青藏高原 东缘四川北部阿坝州九寨沟县发生 7.0 级地 震 (图 1), 震中位于 $\left(33.20^{\circ} \mathrm{N}, 103.82^{\circ}\right.$ E)。据中国地震台网中心 (CENC) 测定, 震 源深度 $20 \mathrm{~km}$ 。

根据中国地震局 2017 年 8 月 18 日网站 公布的消息, 九寨沟县 17 个乡镇的 1680 户 房屋受到损坏。其中, 1037 户轻度受损, 420 户中度受损，223 户重度受损。九寨沟 7.0 级地震已致 25 人死亡, 525 人受伤。九寨沟 Ms7. 0 地震发生在南北地震带中北段, 青藏 高原东缘巴颜喀拉块体内部, 邻近该块体北 边界断裂带 ${ }^{[1]}$ 。

地震产生的主要损失是在近断层区域, 大量震害调查、统计资料表明, 人身伤亡和 


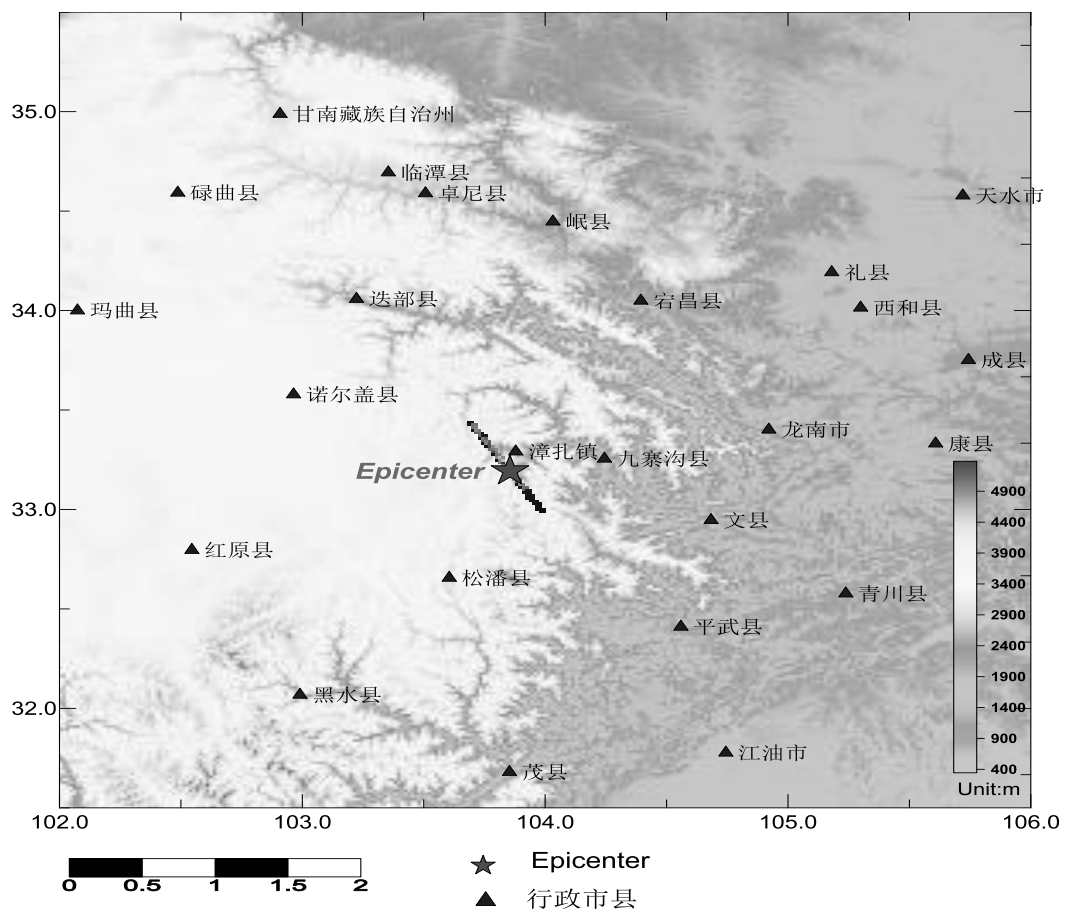

图 1. 九寨沟地震震源位置及周边县市。

经济损失主要是建筑物倒塌破坏、地质灾害 成的, 而工程结构的破坏、倒塌却主要是由 强烈的近场地震动造成的, 近场强震动也是 地基失效、滑坡等其它地震破坏现象的外部
造成的主要是建筑物倒塌破坏、地质灾害造 条件。因此研究分析近场强地面运动的特征, 对于震后救援以及未来建筑抗震设计, 城市 发展规划有很好的指导意义。

四川九寨沟7.0级地震烈度图

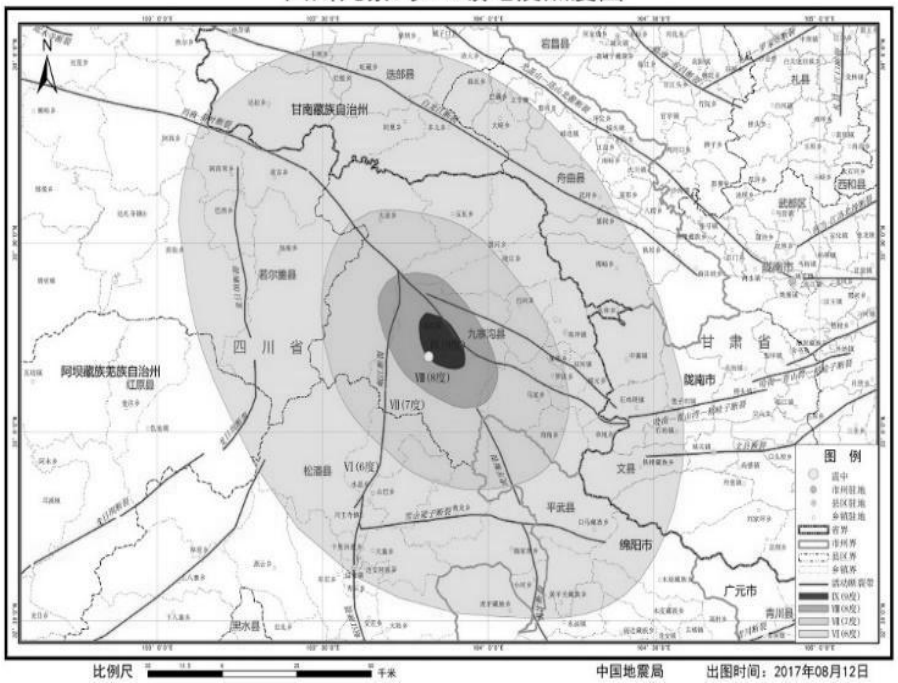

图 2. 四川九寨沟 7.0 级地震烈度图. 地震的最大烈度为IX度. (中国地震局监制, 出图时间 2017.8.12)。 


\section{2. 震害调查及烈度分布情况}

此次地震的最大烈度为IX度 (图 2), 烈 度分布具有一定的对称性 ${ }^{[4]}$, VI度区 (6 度) 及以上总面积为 18295 平方千米。其中IX度 (9 度) 区涉及四川省阿坝藏族芫族自治州 九寨沟县漳扎镇, 面积 139 平方千米。VIII度 （8 度）区涉及四川省阿坝藏族㒸族自治州 九寨沟县漳扎镇、大录乡、黑河乡、陵江乡、 马家乡, 面积 778 平方千米。VII度 (7 度) 区涉及四川省阿坝藏族姜族自治州九寨沟 县、若尔盖县、松潘县, 绵阳市平武县, 面 积 3372 平方千米。VI度（6 度）区涉及四川 省阿坝藏族芫族自治州九寨沟县、若尔盖县、 红原县、松潘县, 绵阳市平武县; 甘肃省陇 南市文县, 甘南藏族自治州舟曲县、迭部县, 面积 14006 平方千米。地震造成四川、甘肃 两省 8 县受灾 (中国地震局震灾应急救援司, 2017)。基于现场考察和强震记录, 中国地 震局给出了本次 Ms7.0 地震的等震线分布, 等震线呈近椭圆形, 长轴走向 NNW, 极震区 烈度达IX度, 长约 $19 \mathrm{~km}$, VIII度区长约 $45 \mathrm{~km}$ 。

此次地震的造成的破坏主要以房屋倒 塌, 道路损坏以及滑坡为主, 部分地区有巨 石滚落发生。此次地震未见有大面积房屋倒 塌的情况发生, 根据抵达九寨沟县城的四川 省地震局现场工作队报告, 九寨沟县城受灾 情况不严重, 未见房屋倒塌开裂、梭瓦现象, 县城社会秩序良好; 路边有小型垮塌, 震中 道路不通; 当地小电网不通。部分地区部分 房屋出现损毁坉塌情况。在距地震灾区九寨 沟县城 130 公里的大录乡亚录寨村受灾严重 (图 3), 大录乡在地震中不同程度受损房屋

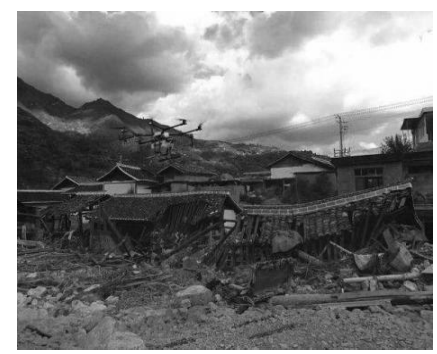

(a)
约 700 多栋, 其中严重受损需重建 26 栋。 地震发生后对于交通的破坏会严重延误震 后救援工作。交通阻塞, 道路损毁（图 4), 山体滑坡等灾害都会增加震后震害的严重 程度, 并造成了世界自然文化遗产九寨沟景 区的严重受损。因此, 该次地震的致灾因子 同芦山地震等有部分差别 ${ }^{[5]}$ 。

九寨沟地震的地震动的峰值加速度小 于同等震级的地震, 例如芦山地震 ${ }^{[2-3]}$, 并且 能量衰减较快。对九寨沟地震的地震动参数 特征研究表明, 此次地震是一次震级较大、 但灾害损毁程度相对较低的地震。九寨沟地 震虽然震级较大, 并造成了一定程度的人员 伤亡, 地震造成的破坏主要是房屋建筑的破 坏, 且大部分房屋建筑在修缮后还可以继续 使用。道路损毁主要体现在滑坡、滚石、路 基塌陷等灾害, 造成了一定程度的交通阻塞, 但没有大面积、长距离的道路损毁现象, 道 路在震后都可以较快的抢修通车, 为震后救 援提供了非常大的便利, 减轻了地震造成的 伤亡和财产损失。

\section{3. 强地面运动记录情况}

强地面运动就是一次地震在地表造成 的各个质点的运动情况, 大家平时看到强震 台的地震波形图其实就是记录到的强地面 运动过程。通常我们以三个物理量来描述强 地面运动的物理过程, 分别是加速度, 速度 以及位移。由于强地面运动是具有方向性, 因此现代地震仪在记录加速度, 速度以及位 移时都要从南北, 东西和垂直三个方向进行 记录。强地面运动可以描述地震发生时表征

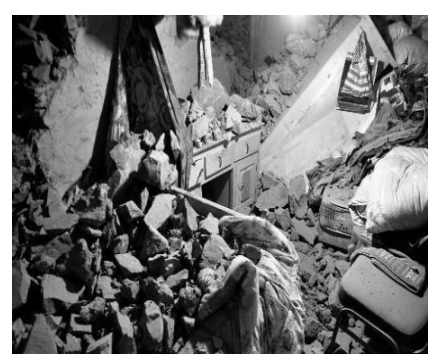

(b)

图 3. 九寨沟地震造成的部分房屋倒塌情况。(图 a 照片来自四川省地震局易桂喜研究员, 图 $\mathrm{b}$ 为大录乡亚 录寨村的房屋损毁, 该村在此次地震中损毁严重)。 


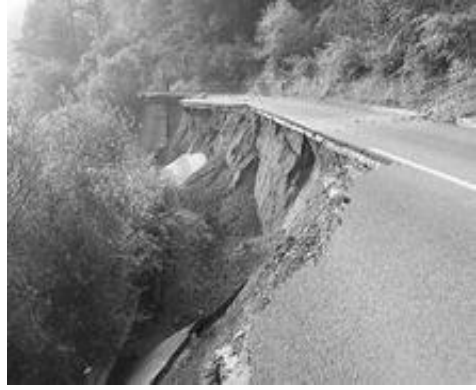

(a)

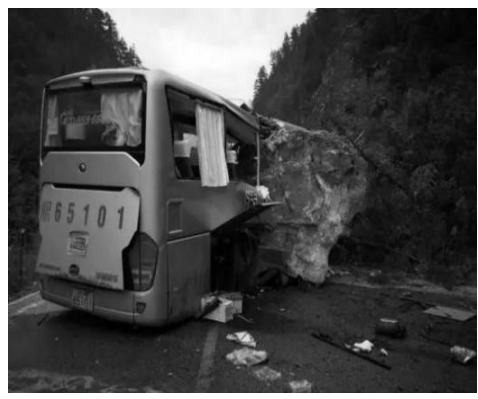

(c)

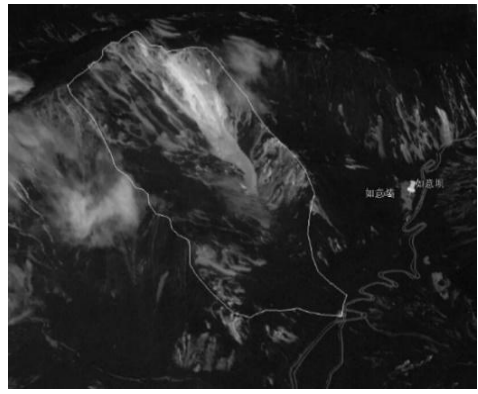

(e)

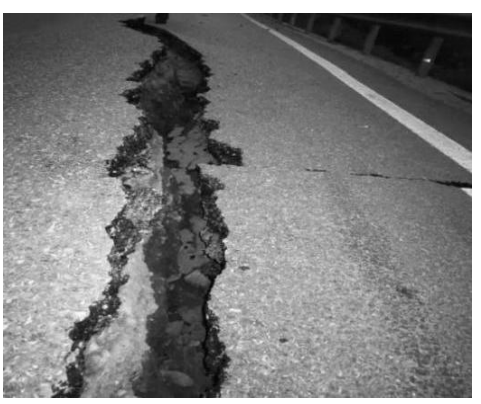

(b)

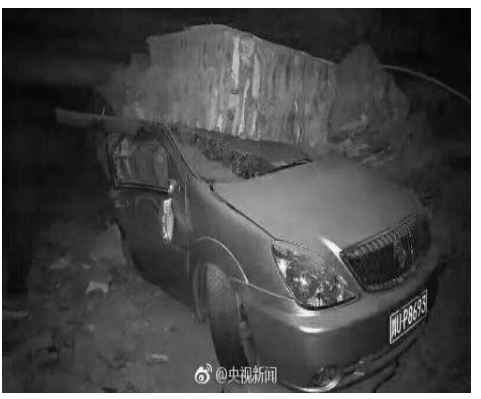

(d)

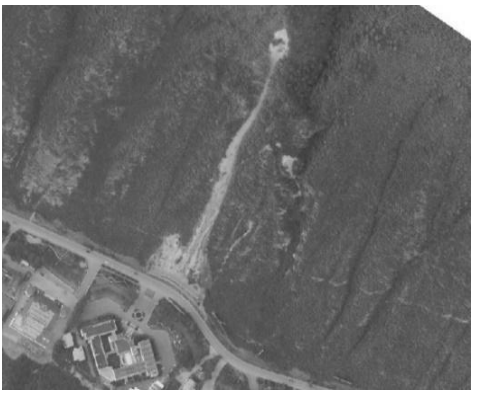

(f)

图 4. 九寨沟地震造成的道路损毁、滑坡、巨石砸中汽车、景观破坏等。

（图 a 照片来自四川省地震局易桂喜研究员，图 b、c、d 照片来自网络; 图 e、f 照片来自中国地震局地 质研究所许冲研究员; 图 c 为四川阿坝州九寨沟县漳扎镇 301 省道, 有落石堵塞出景区道路, 有车辆被巨 大落石砸中；图 e、图 f 为震区如意坝附近的山体滑坡）。

地面运动特征及强度。而地震动参数则是具 体的表征地震强度特征, 能量大小, 破坏特 征的, 峰值加速度 (PGA) 是表征强地面运 动特征的主要参数之一。

本次九寨沟地震, 共收到 46 个强震台 站的地震记录, 其中四川省地震局 18 个台, 甘肃省地震局 8 个台, 陕西省地震局 14 个 台, 宁夏地震局 6 个台。其中九寨百河台 (图 5) 震中距最小, 震中距 32.2 公里, 东西、
南北、垂直向加速度峰值分别为 $-129.5 \mathrm{~cm} / \mathrm{s} 2 、-185.0 \mathrm{~cm} / \mathrm{s} 2 、-124.7 \mathrm{~cm} / \mathrm{s} 2$, 速度峰值分别为 $-3.9 \mathrm{~cm} / \mathrm{s} 、 6.6 \mathrm{~cm} / \mathrm{s}$ 、 $2.5 \mathrm{~cm} / \mathrm{s}$, 计算仪器地震烈度 6.2 度 (国家强 震台网中心强震动观测简报, 2017)。此次 获取的强震数据显示, 大部分台站的 PGA 普 遍小于 $10 \mathrm{gal}$, 地震动分量中超过 $10 \mathrm{gal}$ 的 台站共有 9 个台站。

通过对收集到 46 个台站的峰值加速度 

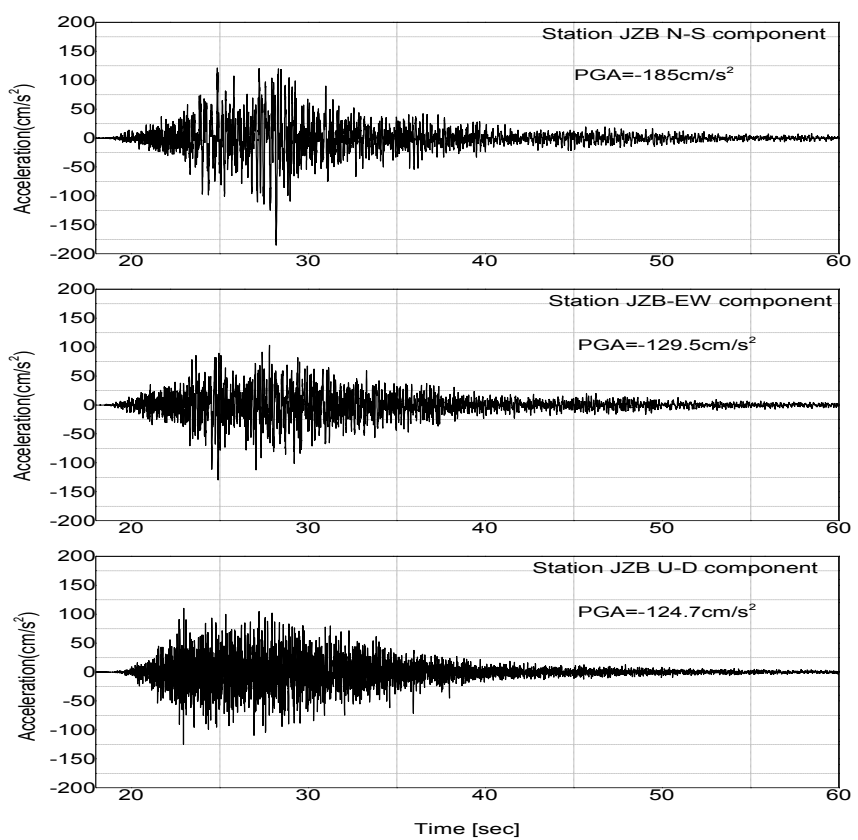

图5. 九寨百合台站051JZB三分量时程图, 此次地震的最大PGA出现在该台站位置。

进行插值拟合, 我们得到九寨沟地震近场区 域的地震动分布特征 (图 6 )。从图 6 来看, 地震动强度从震源向周围整体呈圆形衰减 扩散, 且衰减速度非常快。九寨沟地震属于 典型的走滑型地震, 在靠近震源位置, E-W 方向分量的 PGA 值小于 $\mathrm{N}-\mathrm{S}$ 方向分量的 PGA 值。因为震源东南部台站记录较少的原因, 缺少合适的 PGA 数据进行插值拟合, 所以图 6 显示的 PGA 分布图没有体现出明显的椭圆 形衰减分布特征, 没有明显的长轴和短轴, 还需后期补充震源东南区域地震动 PGA 的反 演分析。通过对现有的 46 个台站 PGA 的插 值拟合我们发现, 此次九寨沟地震释放的情 况以及地震动的整体破坏强度小于同震级 的其他破坏性地震的破坏强度。

\section{4. 结论与讨论}

本文以九寨沟震后灾害调查资料以及 强地震记录为基础, 综合分析了九寨沟地震 的震害特征以及强地面运动参数 PGA 的分布 特征。综合分析结果表明:

（1）此次地震给九寨沟县及附近地区 造成了较大的地震灾害损失, 某些地区山体
滑坡、道路塌陷、巨石滚落等灾害较多。从 地震动特征分析来看, 此次地震的地震破坏 强度比之前同等震级的地震要小, 整体破坏 性程度也要小, 地震动衰减较快。

(2) 九寨沟地震的地震动的峰值加速 度小于同等震级的地震。对九寨沟地震的地 震动参数特征研究表明, 此次地震是一次震 级较大、但灾害损毁程度相对较低的地震。

（3）九寨沟地震发生在九寨沟景区附 近, 地震发生后九寨沟景区需要经过较长时 间的修缮, 会造成较大的间接经济损失。

汶川地震时, 通往震区的道路, 几乎全 部阻断, 给震后救援和赈灾物资的发放造成 了非常大的困难, 这也加重了地震造成的人 员伤亡和财产损失。而九寨沟地震的震源深 度 $20 \mathrm{~km}$, 地质构造较为复杂, 该地区设防烈 度较高、房屋抗震性能较好、人口密度相对 较低, 地震灾后救援迅速, 使得九寨沟地震 的灾害与损毁程度相对较低。此次九寨沟地 震灾害较轻的另一个原因在于汶川地震后, 普遍提高了建筑物的抗震设防能力。此次九 寨沟地震也暴露出的一个问题, 即很多伤亡 是由建筑物的附属构筑物造成的, 地震发生 时墙体填充物的倒塌, 高处位置建筑附属物 
的芏落都会造成意外的伤亡, 这类问题需引 起我们注意, 应该在地震多发区制定相应的 国家规范, 尽量避免或提高此类建筑附属构 来越好, 震后救援的体系流程越来越完善可 筑物的抗震能力。随着我国防震减灾事业的 不断推进, 未来的房屋建筑的抗震性能会越 靠, 这些都会很大程度上降低破坏性地震造 成的人员伤亡和财产损失, 不断减轻破坏性 地震灾害的风险。
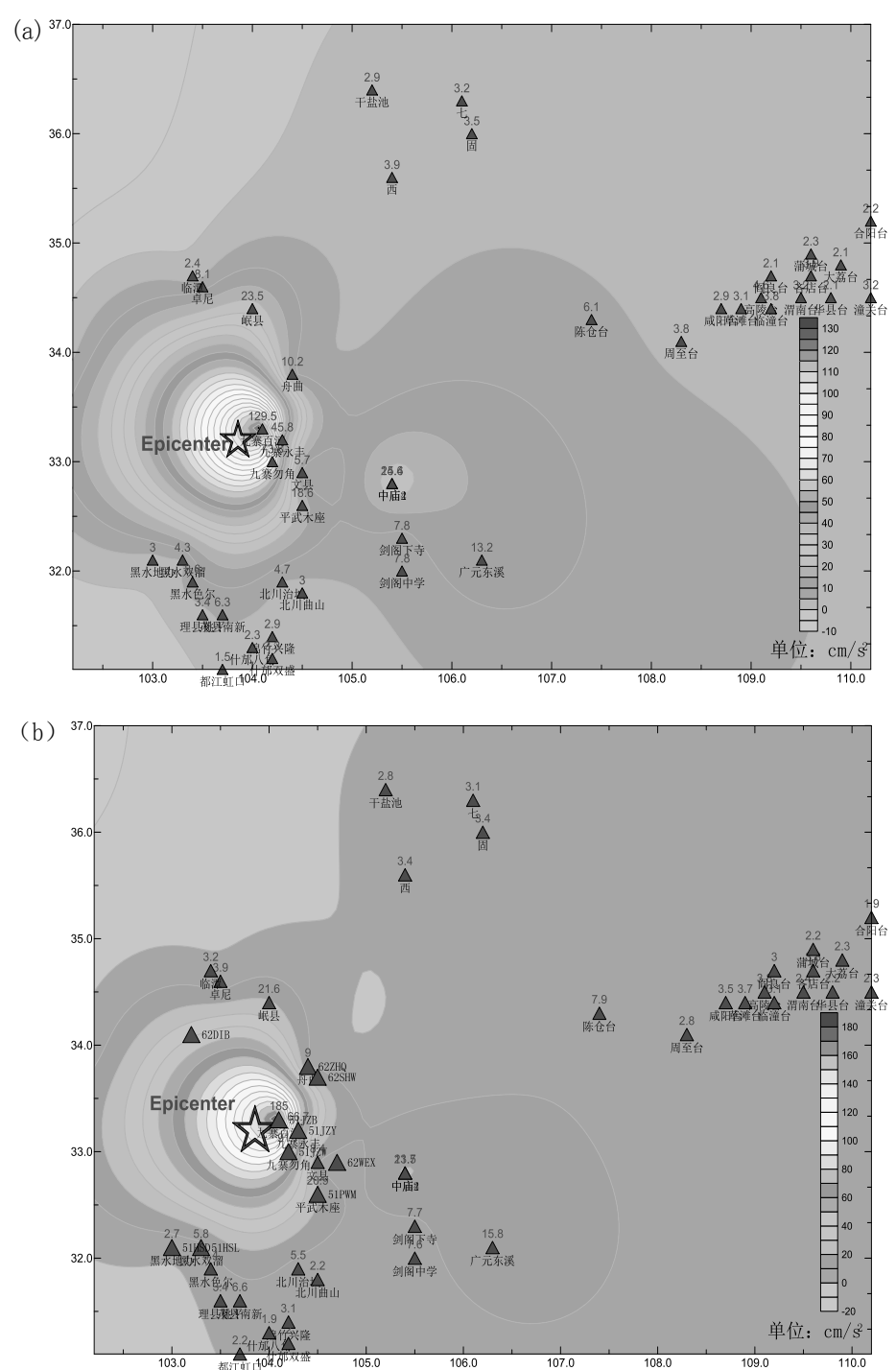

图 6. 九寨沟地震水平分量 PGA 分布图。(a) 为 E-W 方向分量的 PGA 分布特征图; (b) 为 N-S 方向分量的 PGA 分布特征图。

\section{致谢}

本文所用强震数据来自中国地震局工 程力学研究所国家强震台网中心。部分灾害 照片来自四川省地震局和中国地震局地质 研究所, 在此表示感谢。本文受到国家自然
科学基金项目（项目号：51678537, 51278470 ), 重点研发计划 (2017YFC1500205-03); 中国地震局地球物 理研究所基本科研业务费专项资助（编号: DQJB18B20）等项目资助。 


\section{参考文献}

[1] 易桂喜,龙锋,梁明剑,等. 2017 年 8 月 8 日九寨沟 M7.0 地震及余震震源机制解 与发震构造分析.地球物理学报, 2017 , 60(10): 4083-4097.

[2] 乔森, 陈学良, 刘爱文, 温增平, 李小 军.大陆首次超过 $1 \mathrm{~g}$ 的强地面运动记录 特点及震害特征.中国灾害防御协风险 分析专业委员会第六届年会论文集 (2014 年 8 月 23-27 日, 呼和浩特),pp. 20-26.

[3] 陈学良, 高孟潭, 李世成, 崔建文, 郭 金萍, 乔森. 地震矩率函数和龙头山记 录研判鲁甸 6.5 级地震发震断层方向. 中国灾害防御协会风险分析专业委员 会第七届年会论文集(2016 年 11 月 4-6 日, 长沙),pp. 380-386.

[4] Yan J P, Li S S, Bai J, Liu X Y. The spatial symmetry axis of earthquake hazard in China. Journal of Risk Analysis and Crisis Response, 2013, 3(1): 59-64.

[5] He Y. Assessment research of Bijie drought risk based on cloud model.Journal of Risk Analysis and Crisis Response, 2013, 3(4), 192-200. 